\title{
Paroxysmal nocturnal hemoglobinuria
}

INSERM

\section{Source}

INSERM. (1999). Orphanet: an online rare disease and orphan drug data base.

Paroxysmal nocturnal hemoglobinuria. ORPHA:447

Paroxysmal nocturnal hemoglobinuria $(\mathrm{PNH})$ is an acquired clonal hematopoietic stem cell disorder characterized by corpuscular hemolytic anemia, bone marrow failure and frequent thrombotic events. 